\title{
O LUGAR DA AGROECOLOGIA NO CURRÍCULO DOS CURSOS DIRECIONADOS PARA A ÁREA RURAL DO IFFARROUPILHA
}

\author{
Tatiana Aparecida Balem ${ }^{1}$ \\ Gustavo Pinto da Silva ${ }^{2}$
}

\section{RESUMO}

A Agroecologia só se concretizará como paradigma científico e de desenvolvimento quando houver profissionais formados na mesma linha. Os Institutos Federais (IFs), criados em 2008, propõem-se a uma nova institucionalidade, capacitada para promover uma política educacional comprometida com o desenvolvimento local e regional sustentável, além de delinear novas estratégias de inclusão social. Este artigo busca, através da análise documental, revisão bibliográfica e observação, analisar se a Agroecologia se apresenta como paradigma norteador do itinerário de formação dos cursos direcionados para a área rural do IFFarroupilha. Os conteúdos do PDI e os PPCs, presentes nos currículos destes cursos, demonstram certa dissonância frente aos conteúdos que regem o marco legal que institui os IFs. Desse modo, apesar do momento de construção de identidade da nova institucionalidade, é possível evidenciar que os velhos paradigmas ainda estão influenciando nessa nova ideologia. Entretanto, a inserção de ideias, de novos elementos curriculares, bibliografias e de um curso alinhado com o discurso do desenvolvimento sustentável e da Agroecologia podem representar um movimento benéfico e construtivo na formação dos cursos direcionados à área rural no IFFarroupilha.

Palavras chave: agroecologia, formação, I.F. Farroupilha.

\section{THE PLACE OF AGROECOLOGY AT CURRICULUM OF RURAL ORIENTED COURSES OF IFFARROUPILHA}

\begin{abstract}
Agroecology will only materialize as a scientific and development paradigm when professionals trained exist in the same logic. The Federal Institutes (IFs) were created in 2008. It proposes a new institutional framework capable of promoting an educational policy committed to local and regional sustainable development, besides outlining strategies for social inclusion. This article seeks, through document analysis, literature review and observation, analyze whether the Agroecology is a guiding paradigm of training itinerary of rural oriented courses of IFFarroupilha. The content of PPCs and PDI of rural oriented courses of IFFarroupilha demonstrate a certain dissonance with contents of the legal framework that establishing the IFs.

\footnotetext{
${ }^{1}$ Mestra e doutoranda em Extensão Rural pela Universidade Federal de Santa Maria. Professora do Instituto Federal Farroupilha campus Júlio de Castilhos. E-mail: tatianabalem@yahoo.com.br

2 Mestre e doutorando em Extensão Rural pela Universidade Federal de Santa Maria. Professor do Colégio Politécnico da Universidade Federal de Santa Maria. E-mail: gustavo.pinto@politecnico.ufsm.br
} 
This way, despite the moment of construction of the new institution identity's, this may be being built from old paradigms. But the inclusion of ideas, curricular elements, bibliographies and a course aligned with the discourse of sustainable development and Agroecology, may represent a move that will lead to rethink the rural oriented training in IFFarroupilha.

Keywords: agroecology, I.F. Farroupilha, training.

\section{INTRODUÇÃO}

A agricultura convencional vem se reproduzindo para atender o aumento da produção e produtividade e para responder ao padrão desenvolvimentista pensado pelos países centrais (relação centro-periferia). Este processo foi responsável pela simplificação dos processos naturais, o que transforma o fazer agricultura, antes complexo e inter-relacionado com o ambiente, em linear, simples e artificial: linear, porque os sistemas de produção são baseados em pacotes tecnológicos muito similares, independente dos cultivos e das regiões onde são praticados; simples, porque a execução do pacote tecnológico não exige o pensar e o construir a partir das situações concretas determinadas socialmente e ambientalmente. Ao contrário, apenas a execução de tarefas programadas antes do plantio; e, por último, artificial, porque os cultivos e criações são indisciplinados dentro do ecossistema, pois o pacote tecnológico é capaz de prever e resolver eventuais problemas, provocados pelo equilíbrio ou desequilíbrio dos agroecossistemas.

Essa agricultura projetada com fins econômicos, de um lado pela indústria de insumos e maquinário e, de outro, por aqueles agricultores que conseguiram se inserir, responde a um modelo de exploração que, segundo Martinez-Alier (2008), não considera os danos ambientais e a exaustão dos recursos naturais. Assim, a contaminação ambiental, a degradação dos agroecossistemas, a exploração e erosão da biodiversidade não são contabilizadas na exploração agrícola.

As discussões de agricultura sustentável e de desenvolvimento rural vêm a construir um novo paradigma de desenvolvimento. Esses conceitos, segundo Mielgo e Sevilla Guzmàn (1995), evocam a questão agrária e a necessidade de desenvolver uma agricultura diferenciada para alcançar a segurança alimentar e preservação ambiental. O conceito de desenvolvimento rural evoca o empoderamento e a participação dos públicos historicamente alijados do "desenvolvimento", assim como a necessidade de reconhecer a multifuncionalidade dos espaços rurais (Ibidem).

A Agroecologia, nesse sentido, apresenta-se como ruptura paradigmática do "pensar" e "fazer" agricultura. Para Caporal (2009, p. 05), a Agroecologia se propõe a "orientar estratégias de desenvolvimento rural mais sustentáveis e de transição de estilos de agricultura mais sustentáveis". Para o autor, a Agroecologia possui um potencial técnico-científico capaz de reorientar ações de ensino, pesquisa e de assistência técnica e extensão rural, assegurando maior sustentabilidade sócioambiental e econômica para os diferentes agroecossistemas.

Uma das questões fundamentais para um novo paradigma agrícola, baseado na Agroecologia, é a formação dos profissionais que trabalham com a agricultura. Segundo Froehlich (2010, p. 4), "os profissionais das ciências agrárias (técnicos) são as pessoas mais responsabilizadas socialmente pela geração e implementação das tecnologias na agricultura". Com a discussão da sustentabilidade, houve um deslocamento da concepção de ciência, na qual se busca uma visão sistêmica e dinâmica da realidade, baseada em relações e 
transformações permanentes. Dessa maneira, a tecnologia, imposta em receitas isoladas, não atenderá o novo paradigma (lbidem).

Os Institutos Federais de Educação, Ciência e Tecnologia (doravante IFs), criados em $2008^{3}$ a partir da reconfiguração da rede de educação profissional e tecnológica, vêm sendo anunciados como uma nova política de formação profissional. Essa política assume para si a responsabilidade de ser promotora do desenvolvimento local e regional sustentável. Além disso, ela propõe a elaboração de estratégias para a inclusão dos públicos historicamente esquecidos pelos sistemas educacionais brasileiros e pelas políticas desenvolvimentistas (MEC, 2010).

A organização deste artigo busca estabelecer um diálogo entre a Agroecologia, concebida "como nova abordagem da agricultura e do desenvolvimento agrícola", conforme esclarecem Caporal (2009) e Gliessman (2000) (segunda seção), a política para os IFs que propala o desenvolvimento sustentável como condutor da formação (terceira seção) e a formação para o rural, desenvolvida pelo Instituto Federal de Educação Ciência e Tecnologia Farroupilha (doravante IFFarroupilha) (quarta seção).

A investigação é eminentemente qualitativa, desenvolvida a partir de três eixos norteadores: análise documental, reflexão da atuação profissional dos autores e revisão de literatura. A revisão de literatura foi fundamentada em produções que delineiam a política para os IFs, assim como acontece em obras que apresentam referencial para discussão da Agroecologia e sua contribuição para 0 desenvolvimento rural sustentável. A análise documental se realizou a partir do marco legal que estabelece os IFs como política educacional federal, assim como dos Projetos Pedagógicos de Curso (doravante PPCs) dos cursos Técnicos (CT), cursos Superiores de Tecnologia (CST) e do Plano de Desenvolvimento Institucional (PDI) do IFFarroupilha. Por último, a observação foi desempenhada durante a trajetória profissional e dos autores, docentes e pesquisadores, intimamente ligada com a formação para o rural do IFFarroupilha.

Este estudo objetiva analisar a Agroecologia enquanto paradigma orientador da prática formativa dos cursos voltados para o rural do IFFarroupilha. Nesse sentido, procurou-se apontar: Qual o modelo balizador da formação dos CT e CST do IFFarroupilha? Esses cursos correspondem às diretrizes e concepções propostas nos documentos oficiais dos IFs?

Contudo, apesar das limitações desse estudo, realizado a partir de análise documental e observação, as reflexões suscitadas nele podem gerar debates acerca dos rumos da formação nos IFs ou de outras instituições de ensino. Ainda que o caso estudado pertença à rede de educação profissional e tecnológica, as reflexões também se tornam significativas para o ensino superior.

\section{AGROECOLOGIA: UM PARADIGMA PARA A FORMAÇÃO PROFISSIONAL}

A agricultura mundial encontra-se em um período de discussão e de avaliação e, muitas são as contribuições da comunidade científica, na perspectiva de apontar outro caminho. Frente às inúmeras transformações na base produtiva, ocorridas desde a implantação da Revolução Verde, o momento, atualmente, é de uma busca pela ruptura desse paradigma de produção. A necessidade dessa ruptura está ancorada nos efeitos negativos que a agricultura chamada convencional

\footnotetext{
${ }^{3}$ A lei 11.89229 de dezembro de 2008 muda a concepção da educação profissional e tecnológica, institui a Rede Federal de Educação Profissional, Científica e Tecnológica e cria os Institutos Federais de Educação, Ciência e Tecnologia.
} 
tem produzido, sendo o principal fator o distanciamento, cada vez maior, da "agricultura" dos processos naturais e dos problemas sociais. De acordo com Schutter (2010), os avanços alcançados para garantir produção suficiente para a demanda mundial de alimentos, combater a fome e desnutrição, aumentar a produtividade mundial de alimentos são insuficientes para satisfazer as necessidades futuras. As perdas causadas, em longo prazo, pelo modelo convencional de agricultura, principalmente pela degradação progressiva dos agroecossistemas e pelos problemas de contaminação ambiental, põem em risco a capacidade futura de manter os atuais níveis de produção.

O debate em torno da Agroecologia, como proposta de ruptura paradigmática, vem se fortalecendo, justamente por não haver retorno da agricultura convencional sobre os problemas do meio rural. De acordo com o Marco Referencial em Agroecologia da Embrapa, "o termo Agroecologia foi cunhado para demarcar um novo foco de necessidades humanas, qual seja o de orientar a agricultura à sustentabilidade no seu sentido multidimensional" (EMBRAPA, 2006, p. 22).

A Agroecologia, ao contrário da agricultura convencional, busca cumprir simultaneamente a sustentabilidade econômica, ecológica, social, cultural, política e ética (EMBRAPA, 2006). Nesse sentido, é necessário superar a visão de que a Agroecologia seria, simplesmente, para produzir de forma mais limpa, com substituição ou eliminação de determinados insumos (BOECKMANN, SILVA e CAPORAL, 2011). Além disso, como afirma Martinez-Alier (2008), é tempo de pensar um crescimento endógeno, migrando para uma economia mais ecológica, capaz de suprir de forma sustentável as necessidades de alimentação, saúde, educação e moradia, assim como um bem viver acessível a todos. De acordo com Leff (2002), a Agroecologia se apresenta como reação aos modelos agrícolas depredadores e retoma o cultivo da terra como suporte de vida e dos sentidos da existência. Para o autor, a agricultura é o cultivo de culturas, em que os saberes e identidades são convertidos em habilidades e práticas. Essa concepção demanda uma abordagem transdisciplinar da agricultura.

A abordagem transdisciplinar requer uma mudança no pensamento, no estudo e na ciência envolvidos com a agricultura, afastando-se da linearidade proposta pelos receituários técnicos e retornando à complexidade inerente aos ecossistemas naturais. O modelo hegemônico de formação profissional tem acompanhado o princípio da formação disciplinar e compartimentada para resolver os problemas técnicos da agricultura, desse modo o profissional ideal é aquele que domina os conhecimentos especializados.

A parcelização disciplinar precisa ser superada e o enfoque agroecológico se propõe a essa questão, integrando várias disciplinas e distintos saberes, desafiando-se a compreender questões que tem se mantido sem resposta (SEVILLA GUZMÀN, 2002). É necessário compreender: que a ação dos agricultores nos ecossistemas naturais, com a finalidade de produzir "agricultura", acontece pelos seus acúmulos e experiências; que a ação intervencionista, de acordo com os preceitos agroecológicos, é resultado de processos biológicos e tecnológicos, mediados por uma ação socioeconômica e política. Encontrar essas respostas permite compreender e planejar a ação nos agroecossistemas, abstendo-se da visão compartimentalizada e monodisciplinar que tem sido predominante, porém insuficiente.

Para a Agroecologia, é a realidade socioeconômica e ecológica local que define a aplicação da teoria, o que exige, de alguma forma, ajustes mais tênues e apurados em cada situação (EMBRAPA, 2006). A Agroecologia é uma ciência dinâmica e cada manifestação local constrói sua própria forma de tornar o marco teórico concreto, o que reverte as experiências desenvolvidas em marcos de 
orientação, mas nunca modelos fixos a serem seguidos (lbidem). Segundo Leff (2002), é um paradigma que prima pela generalidade e complexidade, pois trabalha com saberes pessoais e coletivos, com o desenvolvimento de habilidades individuais (respeitando os direitos coletivos), que busca soluções tecnológicas para os diferentes contextos ecológicos, prioriza as culturas particulares e, além disso, é uma hibridação de ciências, tecnologias, saberes e práticas.

A orientação transdisciplinar é complexa e, de acordo com cada realidade rural, leva ao agroecossistema uma nova forma de se pensar a agricultura, reconhecendo o componente social como essencial no planejamento da intervenção. A Agroecologia requer uma abordagem fundamentada na construção do conhecimento a partir dos referenciais tecnológicos e científicos e do conhecimento dos agricultores (BALEM, 2004), que co-evoluciona ao longo do tempo e se interrelaciona com as percepções que esses têm ao desenvolver os sistemas de produção. Os agroecossistemas, segundo Gliessman (2000), são locais de produção agrícola que possuem limites arbitrários e representam a unidade de análise para pensar o planejamento, intervenção e o redesenho, quando for necessário. Pois a agroecologia incorpora o funcionamento ecológico necessário para uma agricultura sustentável e compreende a dimensão entrópica da deterioração dos recursos naturais (LEFF, 2002), logo, a ação e manejo não são apenas para preservação dos recursos, mas como também para recuperação daqueles agroecossistemas já erodidos.

No caminho da sustentabilidade, os agroecossistemas necessitam ter características semelhantes aos dos ecossistemas naturais e serem capazes de garantir certa produção agrícola e se perpetuarem ao longo do tempo. Para isso, precisam incorporar, aos moldes dos ecossistemas naturais, resiliência, estabilidade, produtividade e equilíbrio dinâmico (GLIESSMAN, 2000). Essa é uma questão que exige percepção apurada, pois muitos agroecossistemas estão intensamente artificializados e impactados pela agricultura convencional e, ao adotar o paradigma agroecológico, é necessário redesenhar os mesmos. Para que os sistemas de produção sejam desenvolvidos em consonância com a base natural, eles exigem um redesenho que se reporte aos ecossistemas naturais, antes existentes naquele local.

Os sistemas de produção, baseados nos monocultivos e na produção de alguns grãos, ao serem substituídos por sistemas de produção de policultivos, garantem maiores produtividades, melhoram as condições de solo e de equilíbrio para o manejo de pragas e doenças, garantem fluxos de energias mais equilibrados e tendem a diminuir o aporte de insumos externos ao longo do tempo (ALTIERI, 2004). Altieri e Toledo (2011) esclarecem que a Agroecologia poderá: resgatar a natureza, ou seja, colocá-la no centro do planejamento dos agroecossistemas, pois na agricultura convencional os cultivos se desenvolvem indissociáveis das condições naturais; assegurar a soberania alimentar e ponderar os agricultores.

Os benefícios dos agricultores com a Agroecologia centram-se na possibilidade de desenvolvimento de sistemas de produção de acordo com: princípios de manejo dos agroecossistemas intergeracionais; com a cultura e as potencialidades locais, em que a diversidade é valorizada e não considerada empecilho para a agricultura. (Ibidem). Defendendo a linha de raciocínio de Altieri e Toledo (2011), pode-se afirmar que a Agroecologia, ao contrário da agricultura convencional, impactará os agricultores familiares, possibilitando a esses um papel central no cenário político, econômico e produtivo na agricultura.

Considerando Agroecologia como uma ruptura paradigmática na forma de "fazer agricultura", deve-se inferir que a ideia nova surge de um processo de transformação no modo de pensar dos agentes sociais envolvidos. Segundo Morin (2006), as revoluções do pensamento são fruto de abalos generalizados. Para a 
superação de um paradigma, é necessária uma discussão profícua e um tempo de amadurecimento das ideias novas, as quais tendem a serem rejeitadas. De acordo com Kuhn (1987), depois que um paradigma científico estiver totalmente estabelecido, há uma tentativa de forçar a natureza a encaixar-se dentro dos limites pré-estabelecidos e relativamente inflexíveis do paradigma, logo aqueles problemas que não fazem parte do mesmo normalmente são rejeitados.

Neste contexto de disputa de paradigmas, os problemas aceitos pela comunidade científica da agricultura e incorporados nos itinerários formativos dos profissionais de ciências agrárias ainda são, na sua maioria, aqueles encerrados no paradigma da modernização da agricultura que, por sua vez, são os dominantes. Esse paradigma, no intuito de instalar e perpetuar um modelo de produção centrado na tecnificação agrícola a partir de pacotes pré-estabelecidos, torna o agricultor extremamente subordinado à indústria de produção de bens agrícolas (GRAZIANO DA SILVA, 1999). A extensão rural nesse processo e, de acordo com esse paradigma, tem por obrigação repassar os conhecimentos modernos aos agricultores e treiná-los adequadamente para a substituição de conhecimentos tradicionais por estes mais modernos.

No Brasil, a partir de 2003, com a consolidação de um governo democrático e popular, estabeleceu-se a Política Nacional de Assistência Técnica e Extensão Rural (PNATER), a qual constitui um marco de busca pela reconstrução da extensão rural brasileira. A PNATER foi construída com base na premissa de um processo de extensão mais democrático e pela necessidade de inserir estratégias de produção agropecuária que sejam compatíveis com os ideais do desenvolvimento sustentável (MDA, 2009). Nesse parâmetro, a PNATER tem como modelo de desenvolvimento da agricultura a Agroecologia e, como metodologia de ação, a participação. Outro avanço pertinente foi a definição do público alvo, seja ele: agricultores familiares, assentados por programas de reforma agrária, extrativistas, ribeirinhos, indígenas, quilombolas, pescadores artesanais e agricultores, povos da floresta, seringueiros. A política nacional de ATER, lançada em 2004 como decreto presidencial, é consolidada com a Lei $n .12 .188$ de 11 de janeiro de 2010.

Nesse contexto de novas institucionalidades, mudam os desafios e a lógica pela qual as instituições de extensão rural devem focar as ações desenvolvidas. Para cumprir o que a Pnater propõe, exigem-se profissionais munidos de um perfil diferenciado, aptos para atuar em outro modelo de desenvolvimento, profissionais distintos daqueles formados nos cursos moldados para a difusão de tecnologias da Revolução Verde. Conforme afirmam Balem e Donazzolo (2007), o modelo é similar ao da 'Revolução Verde', o qual exigiu uma reformulação completa do perfil dos egressos das instituições de ensino. Agora, busca-se um novo paradigma, fundamentado em um novo enfoque técnico e metodológico, o qual repercute e exige uma nova reformulação dos perfis dos egressos.

Os IFs foram criados com o propósito de reformular as bases da educação profissional e tecnológica. Essa reformulação busca contemplar uma formação mais completa e humanista, capaz de romper com o modelo de treinamento técnico para formar cidadãos preparados para o mundo do trabalho (PACHECO, 2011). O autor ainda salienta que o profissional formado nessa nova concepção deve ser apto para integrar ciência, tecnologia e cultura (dimensões indissociáveis na vida humana) para obter uma atuação em prol do desenvolvimento sustentável com inclusão social. Com essa orientação, é de se esperar que a formação para o meio rural, ofertada pelos IFs, busquem outros referenciais, distantes daqueles balizados pela formação influenciada pela modernização da agricultura. 


\section{UM DIÁLOGO ENTRE O MARCO FORMAL DA EDUCAÇÃO PROFISSIONAL E TECNOLÓGICA E A AGROECOLOGIA}

A criação dos Institutos Federais de Educação, Ciência e Tecnologia em 2008 vem a instaurar novas referências para a formação profissional técnica e tecnológica. Segundo MEC (2010), "o foco dos Institutos Federais será a justiça social, a equidade, a competitividade econômica e a geração de novas tecnologias", assim como a educação profissional e tecnológica terá como ideário a educação como direito e a afirmação de um projeto societário que corrobore uma inclusão social emancipatória, tendo como orientação 0 desenvolvimento territorial sustentável e a formação integral de cidadãos-trabalhadores emancipados.

Uma das áreas de formação dos Institutos Federais de Educação, Ciência e Tecnologia com significativa expressão é as ciências agrárias. Essa herança das antigas Escolas Agrotécnicas vem resultar em vários cursos de nível médio e superior de tecnologia nos IFs. No entanto, o ensino agrícola, baseado na transmissão ordenada e sistemática de conhecimentos tecnológicos, com o objetivo de difundir tecnologias, precisa ser questionado e repensado a partir de uma nova cultura de trabalho e de produção (MEC, SETEC, 2009).

Por um lado, a educação brasileira passa por um amplo processo de debate, voltada à valorização dos sujeitos no seu contexto social e o resgate desses como "sujeitos" e não objetos dos processos educacionais (FREIRE, 1996). Este debate, apoiado em paradigmas holísticos de educação, busca restaurar a totalidade do sujeito, valorizando a sua iniciativa e a sua criatividade, centrada no micro, na complementaridade, na convergência e na complexidade (GADOTTI, 2000).

Para tanto e para não haver resultados contraditórios às Concepções e Diretrizes dos IFs (MEC, 2010; PACHECO, 2011), alguns enfrentamentos precisam ser realizados. O ensino agrícola continua alinhado à lógica da modernização da agricultura, que trata como homogênea a heterogênea realidade rural, tendo como referência o repasse de pacotes tecnológicos, minimizando a participação dos agricultores nas decisões sobre as estratégias de desenvolvimento rural $^{4}$. A estrutura dos campi que oferecem cursos direcionados para o rural realizam os investimentos, sobretudo em tecnologias da agricultura convencional (fertilizantes químicos, agrotóxicos, máquinas e equipamentos) numa tentativa de reproduzir unidades didáticas similares às propriedades "modernas". Os professores que atuam nestes cursos são herdeiros do modelo de formação da agricultura moderna, que segundo Froehlich (2010), foi construído para atender plenamente as exigências do modelo de desenvolvimento, adotado e financiado pelo governo brasileiro, em que a agricultura deveria "financiar o início da industrialização, transferir mão-de-obra para esta, produzir alimentos baratos para baratear a manutenção da mão-de-obra industrial e também consumir produtos industriais, tornando-se um mercado consumidor relevante" (FROEHLICH, 2010, p. 05).

Para discutir e traçar diretrizes para o ensino agrícola da rede Federal de Educação Profissional e Tecnológica, o MEC realizou em 2008 uma série de seminários regionais e um seminário nacional. Destes seminários, resultou um documento intitulado "(Re)significação do ensino agrícola da rede federal de educação profissional e tecnológica" (MEC, SETEC, 2009) que compila uma série de propostas para a reformulação dos currículos dos cursos na área agrícola.

\footnotetext{
${ }^{4}$ Essa afirmação está baseada na experiência e atuação profissional dos autores, assim como na análise documental realizada para essa reflexão. Um dos autores desse artigo também participou dos seminários regionais e do seminário nacional chamado de "(Re)significação do ensino agrícola da rede federal de educação profissional e tecnológica". Esses seminários ocorreram em 2008 e resultaram em uma publicação com indicação de diretrizes para o ensino agrícola em 2009.
} 
Segundo este documento, as transformações ocorridas em todas as áreas da atividade humana na sociedade impõem a necessidade de repensar e reestruturar a educação profissional e tecnológica voltada para o rural, ou seja, uma educação comprometida com as múltiplas necessidades sociais e culturais da população brasileira (MEC, SETEC, 2009). Este documento abrange diversas propostas que apontam para o caminho da reformulação do currículo, baseado em disciplinas e pacotes tecnológicos, tais como:

Incluir nos currículos e programas tecnologias apropriadas para a agricultura familiar que contemplem o associativismo, cooperativismo, sindicalismo e formas de economia solidária. (Proposta, n. 62, p. 30)

Reestruturar o currículo de forma não compartimentalizada, adotando um planejamento participativo como forma de operacionalização e a interdisciplinaridade como dimensão pedagógica unificadora. (Proposta, n. 64, p. 30)

Valorizar e conhecer a Natureza e o Homem a partir de princípios morais e éticos, permitindo o estabelecimento de processos de desenvolvimento cultural e socioambiental adequados. (Proposta, n. 66, p. 30).

Valorizar atividades que possam tornar viável a sustentabilidade das propriedades locais, incorporando o uso da matéria-prima da região, contextualizando os conteúdos para as diferentes realidades da agricultura familiar. (Proposta, n. 77, p. 31)

Essas propostas vêm a romper com a orientação histórica do ensino agrícola, ou seja, com a produção e agricultura convencional intensiva em agroquímicos, balizada pelas grandes indústrias de alimentos, de insumos e maquinários. Segundo MEC e SETEC (2009), o ensino agrícola deve ser capaz de formar profissionais técnicos e politicamente preparados para atender a todas as demandas da sociedade e não somente àquelas representadas pela agricultura empresarial. Além disso, deve ser capaz de reconhecer o público da agricultura familiar e aqueles públicos excluídos ou esquecidos pelo processo de modernização.

Outra questão fundamental apontada pela discussão da ressignificação do ensino agrícola, objeto central dessa investigação, é a necessidade de um novo paradigma técnico-científico, capaz de guiar estratégias para o desenvolvimento sustentável. Neste contexto, a Agroecologia apresenta-se como alternativa de menor agressão ao meio ambiente (Ibidem). O documento também apresenta a Agroecologia como possibilidade de elevação da produtividade, com o mínimo de impacto ambiental em regiões onde predominam a agricultura familiar e em áreas de assentamentos de reforma agrária, contribuindo para a redução da pobreza.

Assim, os cursos, oferecidos pela rede de educação profissional e tecnológica, deveriam trabalhar a agricultura familiar de acordo com as características e especificidades regionais, resgatando conhecimentos tradicionais e melhorando o "fazer agrícola" a partir dos conhecimentos técnicos (Ibidem). Essa concepção corrobora com o que afirmam Caporal, Costabeber e Paulus (2009). A Agroecologia, um campo do conhecimento científico, que parte de um enfoque holístico e uma abordagem sistêmica, alcança, além do manejo ecologicamente responsável, uma nova ética ambiental e intergeracional. É a reafirmação do homem como parte dos agroecossistemas, responsável e capaz de gerar conhecimentos a partir da conjugação dos saberes tradicionais e do conhecimento científico (BALEM, 2004). 
Os IFs precisam, como uma nova institucionalidade, através do ensino, da pesquisa e da extensão, atender os arranjos produtivos locais, no parâmetro da promoção e inclusão social, com abrangência no desenvolvimento sustentável (BRASIL, 2008). Dessa forma, requer um processo educacional construído em uma conjuntura articulada com a comunidade, sendo fundamental a superação da exclusão social e formação de um cidadão apto para o mundo do trabalho (PACHECO, 2011). Assim, o desafio é internalizar esse conjunto de elementos nessas organizações e, se o contexto for educação, é preciso um respaldo nas mudanças políticas, as quais ocorrem no espectro social.

Até o presente momento, percebe-se uma resistência de mudança nas concepções do ensino agrícola, pois ele ainda está atrelado à lógica "modernizante", norte da educação profissional, tais evidências serão salientadas na próxima seção deste artigo. Para Moura (2008), existe a necessidade de formar profissionais que sejam capazes de ultrapassar os limites da percepção estática e homogênea do mundo do trabalho, ou seja, que possam atuar na perspectiva da transformação social, orientada ao atendimento dos interesses e emergências das classes trabalhadoras, embutidos num ambiente de geração do conhecimento. Essa atuação é indispensável para construir uma sociedade que obtenha o ser humano e suas relações com a natureza submetidas a uma racionalidade ética, ao invés de estarem, exclusivamente, a serviço do mercado e do fortalecimento dos indicadores econômicos (MOURA, 2008).

As concepções e diretrizes dos IFs compõem um marco importante de discussão da Educação Profissional e fornecem subsídios para implantar uma proposta diferenciada de formação. No entanto, segundo Souza e Machado (2012), é preciso cuidado e atenção frente à ampliação da discussão in loco para que o discurso oficial da política não permaneça apenas nessa manifestação supérflua. Embora os IFs tenham uma concepção de inclusão e de atendimento às demandas sociais, os velhos modelos estão se repetindo, privilegiando as práticas culturais, tradicionalmente cultivadas pelas classes dominantes (lbidem). $O$ processo de seleção para ingresso nos IFs e a estrutura curricular é um exemplo da falta de avanços na busca pelo modelo propalado pela política e, no caso dos cursos das ciências agrárias, talvez ainda esteja sendo ofertada uma educação, como diria Souza e Machado (2012), adequada aos interesses do grande capital.

\section{CONCEPÇÃO DA FORMAÇÃO DO IFFARROUPILHA: UMA ANÁLISE A PARTIR DO PDI DA INSTITUIÇÃO E DOS PPCS DOS CURSOS DA ÁREA AGRÍCOLA}

O Instituto Federal Farroupilha possui a reitoria na cidade de Santa Maria, região central do estado, e oito campi localizados nas cidades de Júlio de Castilhos (JC), Alegrete, São Vicente do Sul (SVS), Panambi, São Borja (SB), Santa Rosa (SR), Santo Augusto (SA) e Jaguari. De acordo com Plano de Desenvolvimento Institucional (IFFARROUPILHA, 2010), a área de abrangência do IFFarroupilha tem uma grande diversidade de identidades histórico-cultural-econômicas. Geograficamente, os campi estão distribuídos em três mesorregiões do Estado: mesorregião do Centro Ocidental Rio-grandense; mesorregião do Sudoeste Riograndense; e em parte da mesorregião noroeste Rio-grandense, ou seja, nas microrregiões de Cerro Largo, Cruz Alta, ljuí, Santa Rosa, Santo Ângelo e Três Passos. Essa ordenação proporciona uma diversidade de arranjos produtivos locais, culturais, sociais e ambientais. Além disso, são áreas de rebordo da serra, com geografia mais acidentada, de campos sulinos e planalto com relevo ondulado. Algumas microrregiões apresentam como característica notável a forte presença da 
agricultura familiar; em outras, a agricultura empresarial, baseada na presença, em grande proporção, da produção de soja e pela acentuada concentração fundiária em alguns municípios, como por exemplo, Tupanciretã, Júlio de Castilhos e Santiago. Ainda é importante considerar a expressiva presença de assentamentos de reforma agrária na região de abrangência do IFFarroupilha. São 108 assentamentos e 3.902 famílias assentadas (INCRA, 2011).

Ao analisar o Plano de Desenvolvimento Institucional para o Instituto Federal Farroupilha, percebe-se que as questões amplamente discutidas nos documentos que compilam as concepções e diretrizes para essa nova institucionalidade pouco são abordadas e, quando o são, parecem estar descontextualizadas ou tangenciadas. Os fundamentos básicos e princípios do IFFarroupilha não mencionam o desenvolvimento local e regional, nem os arranjos produtivos locais, muito menos, a inclusão social e a educação alicerçada na formação integral do ser humano. No entanto, a tese ambiental aparece em um dos fundamentos, quando o termo sustentabilidade é mencionado ${ }^{5}$. Contraditoriamente, a visão e a missão do Instituto conduzem o desenvolvimento sustentável como meta central da instituição ${ }^{6}$, apesar da discussão do desenvolvimento sustentável estar praticamente ausente na descrição das políticas de ensino, pesquisa e extensão.

Todavia, no transcorrer do texto do PDI aparecem menções das concepções e diretrizes dos IFs, conforme o MEC (2010). De acordo com o PDI, "a construção do Instituto Federal Farroupilha está pautada no compromisso com a construção de um país mais digno e ético e de uma educação que alcance diferentes grupos e espaços sociais" (IFFARROUPILHA, 2010, p. 61). Assim como:

A autonomia dos campi do Instituto atende as necessidades de se buscar o desenvolvimento de Educação Profissional e Tecnológica que considere as diversas representações sociais, desde as grandes empresas, os médios e pequenos empreendimentos e os movimentos sociais, atuando a favor dos arranjos produtivos, sociais e culturais locais (Ibidem).

Outra concepção, diversas vezes mencionada, é a necessidade de trabalhar o desenvolvimento local e regional e de situar os contextos de ensino, pesquisa e extensão com a sociedade, determinada pelo campus que se insere. Percebe-se que, apesar dessas concepções surgirem em alguns pontos do PDI, elas não orientam o documento inteiro, pois, da mesma maneira que se alude à inclusão social, o IFFarroupilha busca ser um centro de excelência em ensino e valorizar os grandes, médios e pequenos empreendimentos com a mesma equivalência. Por outro lado, o instituto reconhece a existência de públicos excluídos, porém indica somente as comunidades indígenas, presentes na área de atuação, ignorando os inúmeros assentamentos de Reforma Agrária, as áreas de predominância da agricultura familiar e as comunidades carentes.

O termo desenvolvimento sustentável virou mote de muitos discursos, no entanto, se analisadas as ações, percebe-se que o discurso não se reverte em

\footnotetext{
5 No último fundamento básico do IFFarroupilha aparece o termo sustentabilidade: "Construir saberes, gerar resultados, tanto na educação básica integrada, como nos técnicos subsequentes, cursos superiores e de pós-graduação, tendo o empreendedorismo e a sustentabilidade como base para a atuação da instituição"(IFFARROUPILHA, 2010, p.04).

6 Missão: Promover a educação profissional, científica e tecnológica, por meio do ensino, pesquisa e extensão, com foco na formação de cidadãos críticos, autônomos e empreendedores, comprometidos com o desenvolvimento sustentável. Visão: Ser referência em educação profissional, científica e tecnológica, como instituição promotora do desenvolvimento regional e sustentável. (IFFARROUPILHA, 2010, p.05)
} 
prática, ou talvez, seja o que afirma Mielgo e Sevilla Guzmán (1995), uma defesa do discurso tecnocrático ${ }^{7}$ da sustentabilidade que não reconhece a acumulação capitalista como origem da atual crise ecológica. Assim, a sustentabilidade assume uma produção mais limpa e de crescimento econômico menos impactante, do ponto de vista do meio ambiente, ou, muitas vezes, é citada em apelo ao discurso politicamente correto e, não, por ser norte de ação ou reflexão.

Concebendo a Agroecologia como pressuposto teórico das concepções dos IFs, presentes no marco legal e nas publicações do MEC, é importante entender em qual lugar se situa a formação profissional voltada ao rural nos campi que integram o IFFarroupilha. Os cursos técnicos e superiores de tecnologia que estão em andamento correspondem aos: Técnico em Agropecuária; Técnico em Agricultura; Técnico em Zootecnia; Técnico em Agroecologia; Técnico em Agricultura de Precisão; CST Agronegócio; CST Produção e Grãos; CST Irrigação e Drenagem. Além destes, o campus de Alegrete oferece os cursos superiores de Zootecnia e Engenharia agrícola, os quais não integram o corpus dessa análise.

De uma forma geral, com exceção do curso de Técnico em Agroecologia, observando o ementário e as bibliografias de cada disciplina, todos os cursos são herdeiros da formação do modelo da modernização da agricultura. O que corrobora com a afirmação de Caporal e Ramos (2006, p 06): "a formação, de nível médio ou universitário, de profissionais para atuação no meio rural continua reproduzindo o modelo de transferência de tecnologia pautado pelos pacotes da Revolução Verde".

A matriz curricular de todos os cursos é composta por elementos disciplinares tradicionais, em que cada disciplina tem a sua carga horária e suas atividades, organizadas, na maioria das vezes, de forma isolada. A interdisciplinaridade, defendida no $\mathrm{PDI}^{8}$, é procurada através de atividades que compõem parte da carga horária das disciplinas do período letivo. Todos os cursos, de acordo com normativa interna do IFFarroupilha, devem realizar "Práticas Profissionais Integradas", que são ações articuladas entre as disciplinas dos períodos letivos correspondentes, as quais devem ser computadas dentro da própria carga horária daquelas envolvidas. Outra ação que envolve interdisciplinaridade enquadra-se nas atividades nomeadas como "práticas interdisciplinares", que buscam uma ação interdisciplinar efetiva no planejamento dos elementos do currículo. Na maioria das vezes, essas práticas introduzem a forma de um projeto integrador, que busca envolver todas as disciplinas do período letivo. Compreendese que a instituição está desenvolvendo, através de políticas internas, estratégias para estabelecer o diálogo e para formular um modelo de educação que constitua interligação entre os componentes curriculares. Por este viés, é possível considerar um avanço.

Como o IFFarroupilha tem como princípio a preservação da autonomia de cada campus, conforme consta no PDI, os mesmos cursos ofertados em campi diferentes têm PPCs distintos. Porém, apesar das diferenças textuais, as matrizes curriculares apresentam profundas semelhanças, como será explicitado a seguir.

O curso Técnico em Agropecuária é oferecido na modalidade Integrado ao Ensino Médio nos campi de AL, JC, SVS e SA e na modalidade subsequente ao

\footnotetext{
${ }^{7}$ Esse discurso reconhece que é impossível um crescimento infinito com recurso finitos e que são necessários corretivos para resolver o problema da deterioração ambiental, no entanto não discute a exploração e os altos índices de consumo dos países do norte, em contrapartida do subconsumo, pobreza e exportação de riquezas dos países do sul (MIELGO; SEVILLA GUZMÀN, 1995).

${ }^{8}$ A integração curricular é um objetivo a ser alcançado. Para atingi-lo é necessária a interlocução entre os conhecimentos oriundos dos diferentes componentes curriculares, atuando como instrumentalizadora dos sujeitos aprendentes, na compreensão da realidade concreta e suas interfaces, e como alternativa na solução de problemas e desafios que esta lhes impõe. (IFFARROUPILHA, 2009, p. 77)
} 
Ensino Médio no campus de JC. Embora os textos gerais de vários PPCs mencionem os termos desenvolvimento local e sustentável, na medida em que se analisam as ementas das disciplinas, esta circunstância não se transpõe para os conteúdos. Nos cursos dos campi de JC e SVS, as disciplinas de Gestão Ambiental e Agroecologia estão presentes na matriz curricular, o que demonstra a intenção de incluir essa discussão no itinerário de formação. No entanto, nos campi de AL e SA a disciplina é somente Gestão Ambiental. Na apresentação da matriz curricular dos campi JC e SVS aparece o seguinte texto:

O desenho curricular do novo curso prevê a interdisciplinaridade entre conhecimentos gerais e específicos correspondentes à formação básica e profissional, além de atender aos princípios ligados à agroecologia, agricultura familiar, movimentos sociais, associativismo, empreendedorismo, pesquisa e extensão, empregabilidade e flexibilidade (IFFARROUPLHA, 2011h e 2011j).

Quando se analisa a grade curricular, os conteúdos das disciplinas e as bibliografias básicas e complementares evidencia-se que a orientação da formação está associada ao modelo de modernização da agricultura. Assim, a formação direcionada à agroecologia, à agricultura familiar, aos movimentos sociais e ao associativismo, como esclarece o excerto acima, torna-se concreta apenas no discurso do PPC ou em alguma bibliografia isolada no ementário da disciplina. Outra questão fundamental é o objetivo geral dos cursos, que nem por um momento, evoca a possibilidade de formar profissionais que sejam capazes de orientar processos produtivos que assegurem a preservação ambiental e uma ação extensionista que faz uso, conforme apontam Caporal e Ramos (2006, p. 07), de:

\begin{abstract}
... tecnologias e de formas de manejo que levem à construção de uma agricultura de base ecológica e, ao mesmo tempo, fortaleçam relações sociais mais equitativas, não só entre os agricultores familiares, mas entre todos os atores envolvidos, de modo a preservar a natureza e caminhar na direção do desenvolvimento rural sustentável. (CAPORAL e RAMOS, 2006, p. 07)
\end{abstract}

Ao contrário do que propõem Caporal e Ramos, os objetivos gerais dos cursos técnicos em Agropecuária ${ }^{9}$ remetem ao perfil profissional voltado à difusão de tecnologias e à instrumentalização para o trabalho com a produção de commodities. O objetivo que segue evidencia esse fator:

O Curso Técnico de Agropecuária Integrado ao Ensino Médio visa à formação de profissional habilitado para atuar, predominantemente junto às empresas rurais, ou como empreendedor, exercendo atividades de planejamento, execução e condução de projetos no ramo da produção vegetal e na área de produção animal (IFFARROUPLHA 2011i, p.06).

No curso técnico em Agropecuária do campus de JC o objetivo geral é:

\footnotetext{
${ }^{9} \mathrm{O}$ curso Técnico em Agropecuária, integrado ao ensino médio do campus de Alegrete, não possui objetivos gerais, somente específicos e todos estão relacionados a uma formação convencional para o modelo da agricultura moderna.
} 
Formar técnicos em agropecuária capazes de atuar no desenvolvimento da matriz produtiva local e regional, principalmente, atendendo às necessidades do mundo do trabalho e promovendo o desenvolvimento com vistas à sustentabilidade econômica, social e ambiental (IFFARROUPLHA 2011h, p.07).

Neste caso, entende-se que há intenção em estabelecer uma formação para o desenvolvimento rural sustentável, o que também pode ser observado em um dos objetivos específicos:

Proporcionar a habilitação profissional em nível técnico, observando-se as exigências e expectativas da comunidade regional, assim como o cumprimento da missão dos Institutos Federais, no que tange à formação propositiva e/ou fomentadora aos arranjos produtivos regionais, sempre com vistas à sustentabilidade (Ibidem).

Porém, ao analisar as ementas e as bibliografias utilizadas no itinerário formativo deste curso, percebe-se que, com exceção de algumas disciplinas (Como por exemplo: Sociologia e Extensão Rural, Fundamentos de Agroecologia, Gestão Ambiental, Solos e Biologia), não há intensão de romper com o modelo agroquímico. Outra contradição perceptível é a presença do curso técnico em Agropecuária no mesmo campus, subsequente ao ensino médio, em que os objetivos não são os mesmos daqueles inseridos na modalidade integrada, como demonstra seu objetivo geral:

Desenvolver, no Instituto Federal Farroupilha - Campus Júlio de Castilhos, o Curso Técnico em Agropecuária na modalidade subsequente ao ensino médio, visando atender à clientela que busca a formação profissional técnica e tecnológica, capazes de fazer frente às necessidades do mundo do trabalho, em constante evolução (IFFARROUPLHA 2011i, p.07).

Resumindo, não há qualquer menção ao desenvolvimento sustentável e ao desenvolvimento regional, o que acaba por revelar que os textos dos PPCs talvez representem mais o desejo de quem os escreve do que uma concepção de formação norteadora do processo educativo. Quando analisados os objetivos específicos e as competências a serem trabalhadas com os futuros técnicos em agropecuária, na maioria dos campi, o desenvolvimento local, o desenvolvimento rural sustentável e a Agroecologia não são mencionados ${ }^{10}$, o que demonstra, desse modo, que esses conceitos não permeiam o itinerário de formação oferecido por esses cursos. O curso técnico em Agropecuária, subsequente ao Ensino Médio do campus de JC, possui um elemento curricular que não consta nos outros PPCs, a disciplina de Fundamentos de Agroecologia. Entretanto, analisando todo o contexto de formação desse curso, é possível considerar esse elemento curricular como sistema isolado e, por vezes, contraditório, incluso num cenário aonde a formação conduz para outro modelo de agricultura.

Os cursos técnicos em Agricultura e Zootecnia possuem contextos muito similares com o da Agropecuária. Em contrapartida, do ponto de vista de outra concepção de formação para o rural, estes cursos são ainda mais estreitos, pois o

${ }^{10}$ Com exceção do curso técnico em Agropecuária, integrado no campus Júlio de Castilhos, como já foi ressaltado anteriormente. 
técnico em Agricultura é formado para trabalhar com sistemas de produção vegetal, enquanto que o técnico em Zootecnia visa o trabalho com sistemas de produção animal. Nesse horizonte, como afirma Leff (2002), a formação está encerrada no modelo da agronomia capitalista, fundamentado na crença do mercado e na especialização tecnológica, desnaturalizando a natureza e a relação do homem com a terra.

No entanto, no PPC do curso técnico em Agricultura, ofertado por apenas um campus, aparecem algumas questões inovadoras, no que tange à discussão da Agroecologia e ao desenvolvimento sustentável, pois dentre os saberes almejados pelo técnico em Agricultura encontram-se os seguintes: "desenvolver tecnologias, principalmente, que promovam a sustentabilidade do meio rural e com isso a permanência do homem no campo com qualidade de vida para esse e sua família" e "disseminar o cultivo em bases ecológicas" (IFFARROUPLHA, 2011f, p. 09). O objetivo geral desse curso também apresenta avanços, na perspectiva de amparo e criações de novas bases, pois o curso busca "empreender um processo educativo que favoreça o desenvolvimento de indivíduos, dotados de capacidade crítica, de autonomia intelectual, eticamente responsável e comprometido com a resolução dos problemas técnicos, sociais e ambientais" (Ibidem, p. 06). Destaca-se também um dos objetivos específicos, o qual visa:

estimular o fortalecimento do vínculo das pessoas com o meio rural, proporcionando a construção do seu conhecimento empírico/científico baseado nos princípios da ética, da sustentabilidade ambiental e econômica e da produção segura de alimentos (Ibidem, p.06).

O curso técnico em Agroecologia na modalidade subsequente, ofertado pelo campus de Alegrete, representa um avanço para uma formação direcionada, conforme explicitada no ponto central da discussão deste artigo. No entanto, a contextualização situacional do PPC, a qual busca justificar a criação do técnico em Agroecologia, não condiz com o marco teórico da mesma. O texto é praticamente o mesmo do curso técnico em Agropecuária e, embora mencione a agricultura familiar e a necessidade de promover estratégias que privilegiem os excluídos do sistema agrícola, não oferece a devida solidez teórica capaz de situar o curso em uma proposta formativa realmente agroecológica. O texto a seguir exemplifica isso.

Reiterando, as ações decisórias que têm encaminhado o desenvolvimento da agricultura brasileira, representadas pela intervenção tecnológica na fertilidade do solo e pela alteração genética da planta, entre outras conquistas, exigem dimensionar, sobremaneira, o perfil do Técnico em Agroecologia, que deverá incorporar em seu padrão técnico diferencial, quer seja pelas questões aqui levantadas, quer seja pelas exigências advindas da globalização, que perpassam todas as etapas das atividades produtivas (do plantio às práticas comerciais) (IFFARROUPLHA 2011e, p. 15).

Frente aos objetivos do curso, é possível perceber um alinhamento maior com as concepções teóricas da Agroecologia, como pode ser observado a seguir:

Buscar a criação de um curso de formação profissional em Agroecologia que propicie aos jovens do campo e aos movimentos sociais um projeto alternativo de desenvolvimento ao modelo econômico regional; Procurar estimular e fortalecer 
o vínculo do jovem com a sua unidade de produção familiar, sua família, grupo e comunidade proporcionando formas de produção baseada na solidariedade, na ética e no respeito ao ser humano, ao ambiente em que vive, fortalecendo o espírito crítico, associativo e cooperativo; Atender a demandas na área educacional, de diferentes segmentos sociais, especificamente do campo, visto que, geralmente o ensino médio foi até o presente voltado para as demandas das empresas rurais; Desenvolver no estudante a autonomia, a capacidade de pensar e estabelecer relações, refletindo sobre essas existentes com seus semelhantes e demais seres vivos, bem como com toda a sociedade, construindo uma postura crítica; Reconstruir o atual modelo rural, através de novos referenciais de mundo, compreendendo 0 global, relacionando-o criticamente com o local, reavaliando-o constantemente para a adequada inserção em questões interpessoais, sociais e mundiais, colocando o conhecimento a serviço da humanidade; possibilitar ao estudante o processamento autônomo do conhecimento coletivamente construído, transformando-o em ações de desenvolvimento rural sustentável. (IFFARROUPLHA 2011e, p. 15).

O perfil do egresso, traçado pelo PPC do curso técnico em Agroecologia, revela que a proposta está baseada, conforme indicam Caporal e Ramos (2006), em um profissional que promova o desenvolvimento rural sustentável, com ênfase em processos endógenos, perpassados pela abordagem sistêmica e multidisciplinar, em processos participativos e organizativos, além de trabalhar num paradigma tecnológico norteado pela Agroecologia. Tais particularidades são imprescindíveis para trabalhar com extensão rural agroecológica. Embora o curso esteja organizado da mesma forma que os demais, ou seja, com base em elementos curriculares ou disciplinas específicas, a grade curricular, as ementas e as bibliografias buscam contemplar uma formação agroecológica. Os elementos curriculares são inovadores, quando comparados aos outros presentes nos cursos da área rural, os quais incluem disciplinas como: filosofia, ética e meio ambiente; manejo ecológico do solo; agroindústria familiar; agricultura e agroecologia; dinâmica e organização dos agroecossistemas; sistemas agroflorestais; plantas bioativas; paisagem e bioarquitetura; entre outros. Além disso, este curso técnico se propõe a discutir a formação em outros parâmetros, distintos daqueles do paradigma capitalista dominante, dessa maneira, pode ser considerado como inovador na proposta formativa do IFFarroupilha.

A orientação para o modelo da agricultura convencional nos CSTs é mais intensa do que nos cursos de nível médio. As áreas que estes cursos abrangem estão intimamente ligadas às questões técnicas específicas das grandes cadeias de produção do agronegócio da região de alcance do IFFarroupilha, como já sugerem os próprios nomes dos cursos, tais como: CST Irrigação e Drenagem; CST Agronegócio e CST Produção de Grãos. Os objetivos destes comprovam essa orientação:

Formar profissionais cidadãos com senso crítico e ético, com competências e habilidades voltadas para o desenvolvimento e utilização de técnicas aplicadas aos sistemas de produção de grãos e sementes. Qualificar um profissional com uma visão geral das ciências agrárias, econômicas, políticas e sociais, e com uma visão especializada da produção de grãos e sementes e do gerenciamento de propriedades rurais, de 
unidades de beneficiamento de sementes e de escritórios e/ou empresas agropecuárias (IFFARROUPLHA 2011d, 2011, p. 06).

Formar profissionais cidadãos com senso crítico e ético, com competências e habilidades voltadas para o desenvolvimento e utilização de técnicas aplicadas aos sistemas de produção de grãos e sementes (IFFARROUPLHA 2011c, p. 06).

Formar profissionais cidadãos com senso crítico e ético, com competências e habilidades voltadas para o desenvolvimento e utilização de técnicas aplicadas aos sistemas de produtivos com ênfase ao agronegócio regional (IFFARROUPLHA, 2011b, p. 05).

Promover a profissionalização gerencial pela capacitação que atenda as exigências das atividades do agronegócio através de elementos que permitam o desenvolvimento econômico e social da região (IFFARROUPLHA, 2011a, p. 05).

Ofertar educação profissional e tecnológica que contribua para o aprimoramento das técnicas e tecnologias envolvidas no processo de irrigação e drenagem, formando e qualificando cidadãos com vistas na atuação profissional na agricultura irrigada, com ênfase no desenvolvimento socioeconômico local, regional e nacional. (IFFARROUPLHA 2012, p. 05).

Da mesma forma em que ocorre nos cursos técnicos, algumas ementas de disciplinas dos CSTs buscam introduzir o debate da Agroecologia e do desenvolvimento rural sustentável, porém desprovido de profundidade e coerência entre o itinerário formativo e o que o curso se propõe em seus objetivos basilares, a concepção desses cursos perde a oportunidade de incluir elementos que poderiam auxiliar nas discussões das relações de poder e de exclusão que, por vezes, os sistemas de produção dominantes e interligados ao grande empresariado da agricultura brasileira deixam a desejar. As consequências desse fator culminam no reforço da matriz produtiva concentradora e na desconsideração dos públicos priorizados pela PNATER brasileira.

Para Caporal e Ramos (2006), a formação deveria ser capaz de construir e orientar profissionais aptos para propor processos adequados a cada realidade e a desenvolver ou adaptar tecnologias e formas de manejo que levem a constituição de uma agricultura com base ecológica. Entretanto, a formação proporcionada pelo IFFarroupilha está longe de superar o enfoque linear e cartesiano das ciências agrárias, formatadas para o modelo agroquímico, como mencionam os autores.

Observa-se que as bibliografias utilizadas nas ementas das mesmas disciplinas são diferentes em função do campus em que são oferecidos os cursos, ou seja, em alguns campi há a preocupação de trabalhar com referências agroecológicas (como é o caso das disciplinas de Manejo do Solo, Olericultura e Fruticultura); em outros, o enfoque é as bibliografias reconhecidas por priorizar o modelo de produção convencional. Tal constatação leva a um questionamento: o ementário e a concepção da disciplina estão relacionados com uma proposta institucional que reconheça a Agroecologia como um dos caminhos para a construção do desenvolvimento sustentável ou com o perfil do professor que a concebe?

Caporal e Ramos (2003, p. 08), ao analisar as instituições de Assistência Técnica e Extensão Rural (ATER), afirmam que as mudanças necessárias para que o paradigma agroecológico se sobressaia ao convencional exigem uma reforma generalizadora no antigo modelo de organização e de gestão das entidades. No entanto, "as mudanças de organização e de gestão, embora desejáveis, são difíceis 
e, geralmente, são caracterizadas por um momento de desordem e de redução temporária da eficiência operacional" (Ibidem).

A falta de clareza teórica do referencial histórico de atuação e, talvez a temeridade de alterações no que está organizado e um pouco equilibrado, levam as instituições a resistir à mudança. Resistência, que Caporal e Ramos (2003), observam nas instituições de ATER e que pode ser a mesma enfrentada pelos IFs, os quais preferem continuar limitados na formação direcionada para o modelo da modernização da agricultura a romper com esse paradigma. Apesar desse diagnóstico, a inserção de ideias, elementos curriculares, bibliografias e de um curso alinhado com o discurso do desenvolvimento sustentável e da Agroecologia podem representar um movimento significante, além de incentivar e influenciar, num momento próximo, grupos colegiados, coordenações e direções dos cursos, a repensarem a formação voltada a área rural do IFFarroupilha.

\section{CONSIDERAÇÕES FINAIS}

A Agroecologia reconecta a agricultura aos ecossistemas naturais, conduzindo o saber de agricultoras e agricultores em diálogo consonante com o saber científico, numa hibridação de conhecimentos. Nesse contexto holístico e complexo, as soluções tecnológicas não estão presentes em receituários e precisam ser construídas com base no conhecimento científico, nos saberes dos agricultores e nas especificidades dos agroecossistemas. Assim, existe a necessidade de profissionais que sejam capacitados para promover processos de extensão rural e a sustentabilidade ambiental, econômica e social do rural.

As orientações do MEC sugerem que as transformações, ocorridas em todas as áreas da atividade humana na sociedade, imponham a urgência de se repensar e reestruturar a educação profissional e tecnológica direcionada para o rural, pois é preciso uma educação comprometida com as múltiplas necessidades sociais e culturais da população brasileira. No entanto, a formação, ofertada pelo IFFarroupilha, ainda está restrita ao modelo da modernização da agricultura. Além disso, os conteúdos presentes no PDI e nos PPCs demonstram um distanciamento da realidade local, uma vez que ignoram a presença massiva de públicos, tais como a agricultura familiar e assentamentos de Reforma Agrária.

Este modelo de formação concebe a realidade rural como homogênea a heterogênea e abarca um modelo tecnológico hegemônico como referência a ser seguida, minimizando a participação dos agricultores nas decisões sobre as estratégias de desenvolvimento rural. Esta formação é contraditória ao que afirmam as Concepções e Diretrizes dos IFs, as quais propalam seus objetivos para o desenvolvimento local e regional, com amplitude à sustentabilidade.

Os conteúdos do PDI e os PPCs dos cursos voltados para o rural do IFFarroupilha demonstram uma certa dissonância frente aos conteúdos do marco legal, que institui os IFs. Dessa maneira, é possível evidenciar que, apesar de ser um momento de busca por uma nova identidade institucional, os velhos paradigmas ainda estão presentes nesta nova idealidade.

Entretanto, conforme enfatizado anteriormente neste artigo, a inserção de ideias, elementos curriculares, bibliografias e de um curso alinhado com o discurso do desenvolvimento sustentável e da Agroecologia, podem representar um movimento progressivo, no qual poderá, futuramente, conduzir para o repensar da formação direcionada para a área rural no IFFarroupilha. Esta pesquisa apresentou apenas um diagnóstico inicial do itinerário formativo destes cursos. Uma proposta interessante de pesquisa seria identificar quais questões determinam, ou não, a busca pela construção dos cursos alinhados com os preceitos do desenvolvimento 
sustentável e ao da Agroecologia. Outra questão importante é compreender até que ponto o discurso da nova institucionalidade, presentes nos documentos oficiais dos IFs, estão apropriados para a comunidade acadêmica.

\section{REFERÊNCIAS}

ALTIERI, M. Agroecologia: a dinâmica produtiva da agricultura sustentável. Porto Alegre: Editora da UFRGS, 2004.

ALTIERI, M.; TOLEDO, V. M. La revolución agroecológica em Latinoamérica: rescatar la naturaleza, asegurar la soberanía alimentaria y empoderar al campesino. SOCLA: 2011. Disponível em: <http://migre.me/rfcMn >. Acesso em 10 de março e 2013.

BALEM, T. A.; DONAZZOLO, J. Formação Profissional nas Ciências Agrárias: um desafio para o desenvolvimento Sustentável. Rev. Bras. de Agroecologia, v.2, n.1, p.322-325, 2007.

BALEM,T. A. Um Processo de Transição Agroecológica: o caso da Associação Nossa Senhora Aparecida. 2004. 119f. Dissertação (Mestrado em Extensão Rural) Universidade Federal de Santa Maria, Santa Maria, 2004.

BOECKMANN SILVA, M.; CAPORAL, F. R.. Agroecologia: Uma Ciência para além da substituição de insumos. In: Congresso Brasileiro de Agroecologia, 7., 2011, Fortaleza. Anais... Fortaleza: ABA, 2011.

BRASIL. Lei 11.892 de 29 de dezembro de 2008. Institui a Rede Federal de Educação Profissional, Científica e Tecnológica, cria os Institutos Federais de Educação, Ciência e Tecnologia, e dá outras providências. Diário Oficial da República Federativa do Brasil, Brasília, DF, 30 de dez. 2008. Disponível em: $<$ http://migre.me/rfcKi >. Acesso em 02 de abril de 2012.

Lei 12.188 de 11 de JANEIRO de 2010. Institui a Política Nacional de Assistência Técnica e Extensão Rural para a Agricultura Familiar e Reforma Agrária - PNATER e o Programa Nacional de Assistência Técnica e Extensão Rural na Agricultura Familiar e na Reforma Agrária - PRONATER, altera a Lei no 8.666, de 21 de junho de 1993, e dá outras providências. Disponível em: < http://migre.me/rfcHJ >. Acesso em 02 agosto de 2012.

CAPORAL, F. R. Agroecologia: uma nova ciência para apoiar transição a agriculturas mais sustentáveis. Brasília: 2009. Disponível em: <http://migre.me/rfcJ7>. Acesso em 23 fev. 2015.

CAPORAL, F. R.; COSTABEBER, J. A.; PAULUS, G. Matriz disciplinar ou novo paradigma para o desenvolvimento rural sustentável. In: CAPORAL, F. R. (org.); COSTABEBER, J. A.; PAULUS, G. Agroecologia: uma ciência do campo da complexidade. Brasília: 2009. p. 65-112.

CAPORAL, F. R.; RAMOS, L. DE F. Da extensão rural convencional à extensão rural para o desenvolvimento sustentável: enfrentar desafios para romper inércias. Brasília, 2006. Disponível em: < http://migre.me/rfcMU>.Acesso em 19 março de 2013. 
EMPRESA BRASILEIRA DE PESQUISA AGROPECUÁRIA (EMBRAPA). Marco referencial em agroecologia. Brasília: Embrapa Informação Tecnológica, 2006.

FREIRE, P. Pedagogia da autonomia: saberes necessários a prática educativa. São Paulo: Paz e Terra, 1996.

FROEHLICH, J. M. A novelesca reforma curricular das ciências agrárias e a sustentabilidade: novas demandas, velhos problemas. Rev. Bras. de Agroecologia. v.5,n.2: p.3-15, 2010.

GADOTTI, M. Perspectivas atuais da educação. São Paulo em Perspectiva, v. 14, n.2, 2000. Disponível em: http://www.scielo.br/pdf/spp/v14n2/9782.pdf. Acesso em: 19 ago. 2011.

GLIESSMAN, S. Agroecologia: processos ecológicos em agricultura sustentável. Porto alegre: Editora da UFRGS, 2000.

GRAZIANO DA SILVA, J. Tecnologia e agricultura familiar. Porto Alegre: Editora da UFRGS, 1999.

IFFARROUPILHA. Plano de desenvolvimento institucional (PDI). Santa Maria: IFFARROUPILHA, 2010.

IFFARROUPILHA. Projeto pedagógico: curso superior de tecnologia Irrigação e Drenagem campus São Vicente do Sul. São Vicente do Sul: IFFarroupilha, 2012.

Projeto pedagógico: curso superior de tecnologia Agronegócio campus Santo Augusto. Santo augusto: IFFarroupilha, 2011a.

Projeto pedagógico: curso superior de tecnologia Agronegócio campus Júlio de Castilhos. Júlio de Castilhos: IFFarroupilha, 2011b.

Projeto pedagógico: curso superior de tecnologia Produção de Grãos campus Alegrete. Alegrete: IFFarroupilha, 2011c.

Projeto pedagógico: curso superior de tecnologia Produção de Grãos campus Júlio de Castilhos. Júlio de Castilhos: IFFarroupilha, 2011d.

Projeto pedagógico: curso técnico em Agroecologia modalidade integrado ao ensino médio campus Alegrete. Alegrete: IFFarroupilha, 2011e.

Projeto pedagógico: curso técnico em Agricultura modalidade subsequente ao ensino médio campus São Vicente do Sul. São Vicente do Sul: IFFarroupilha, $2011 f$.

Projeto pedagógico: curso técnico em Agropecuária modalidade subsequente ao ensino médio campus Júlio de Castilhos. Júlio de Castilhos: IFFarroupilha, 2011g.

Projeto pedagógico: curso técnico em Agropecuária modalidade integrado ao ensino médio campus Júlio de Castilhos. Júlio de Castilhos: IFFarroupilha, 2011h. 
Projeto pedagógico: curso técnico em Agropecuária modalidade integrado ao ensino médio campus Santo Augusto. Santo Augusto: IFFarroupilha, $2011 \mathrm{i}$.

Projeto pedagógico: curso técnico em Agropecuária modalidade integrado ao ensino médio campus São Vicente do Sul. São Vicente do Sul: IFFarroupilha, 2011 j.

INSTITUTO DE COLONIZAÇÃO E REFORMA AGRÁRIA (INCRA). Projetos de reforma agrária conforme fase de implantação. Brasília: MDA/INCRA, 2011. Disponível em: <http://pfdc.pgr. mpf.gov.br/atuacao-e-conteudos-deapoio/publicações/reforma-agraria/questao-fundiaria/assentamentos_2001_a_2010. pdf >. Acesso em: 17 mar. 2013.

KUHN, T. S. A Estrutura das Revoluções Científicas. São Paulo: Editora Perspectiva, 1987.

LEFF, E. Agroecologia e saber ambiental. Agroecol. e Desenv. Rur. Sustentável, Porto Alegre, v.3, n.1, p. 36-51, 2002.

MARTINEZ-ALIER, J. Idiomas de valoração. Boletim da Sociedade Brasileira da Economia Ecológica, n. 19, set-dez., p.17-26, 2008.

MIELGO, A. M. A.; GUZMÁN, E. S. El discurso ecotecnocrático de la sostenibilidad. In: MARÍN, A. C. Agricultura y desarrollo sostenible. Madrid: Ministério de Agricultura, Pesca y Alimentacion, 1995.

MINISTÉRIO DA EDUCAÇÃO (MEC). Institutos Federais de educação ciência e tecnologia: um novo modelo de educação profissional e tecnológica, concepções e diretrizes. Brasília: MEC, 2010.

MINISTÉRIO DA EDUCAÇÃO (MEC). SECRETARIA DA EDUCAÇÃO PROFISSIONAL E TECNOLÓGICA (SETEC). (Re)significação do ensino agrícola da rede federal de educação profissional e tecnológica. Documento Final. Brasília: Brasil, 2009.

MINISTÉRIO DO DESENVOLVIMENTO AGRÁRIO (MDA). Política Nacional de ATER: assistência técnica e extensão rural. Brasília: MDA, 2008.

MORIN, E. O método1: a natureza da natureza. Porto Alegre: Sulina, 2006.

MOURA, D. H. A formação de docentes para a educação profissional e tecnológica. Ver. Bras. da Ed. Profissional e Tecnológica, v. 1, n. 1, Brasília, p. 23-38, 2008.

PACHECO, E. Institutos federais: uma revolução na educação profissional e tecnológica. Brasília: Fundação Santillana; São Paulo: Moderna, 2011.

SCHUTTER, O. de. El derecho a la alimentación. Organizações das nações unidas (ONU); Consejo de Derechos Humanos, 2010. Disponível em: http://www. agroeco.org/ socla/pdfs/ informe-UN-agroecologia.pdf. Acesso em: 10 mar. 2013.

SEVILLA GUZMAN, E. A perspectiva sociológica em Agroecologia: uma sistematização de seus métodos e técnicas. Agroecol. e Desen. Rur. Susten., Porto Alegre, v.3, n.1, jan/mar, 2002. 
SOUZA, J. C. M. de; MACHADO, M. M.. O (não) lugar da educação dos trabalhadores. ENCONTRO DE PESQUISA EM EDUCAÇÃO DA ANPED CENTROOESTE, 11., 2012, Corumbá. Anais... Corumbá:UFMS campus Pantanal, 2012. 